\title{
Impact of interprofessional oral health care
}

This article was published in the following Dove Press journal:

Pediatric Health, Medicine and Therapeutics

14 December 2015

Number of times this article has been viewed

\section{Laura S Larsson}

College of Nursing, Montana State University, Bozeman, MT, USA
Correspondence: Laura S Larsson College of Nursing, Montana State University, I 73560 Sherrick Hall, Bozeman, MT 59717-3560, USA Tel +l 4069947504

Email llarsson@montana.edu

\section{Dear editor}

I read with enthusiasm the evaluation results of Colorado's oral health education (OHE) initiative reported by Braun et al. ${ }^{1}$ As the health care community attempts to address the problem of persistent early childhood caries, expanding service delivery to nontraditional environments and expanding the scope of practice to non-dental providers are both promising ideas. I applaud Colorado and the other states where they have tied Medicaid reimbursement for non-dental providers to completing an OHE training program. I further applaud the effort of Braun and her team to evaluate the policy initiative. As other states consider how to move forward, it should be helpful for them to read the results of the strategies tested in Colorado.

I did wonder if clarification on three points would improve the utility of the reported work for use by other states and public health professionals working in rural and remote areas. First, in the narrative about "effectiveness" the authors stated they compared participants' pre-/post-training scores on key variables but in the results for "effectiveness," it appears the comparison was between provider types instead. Did the authors perform chi-square tests to compare medical professionals' change from baseline? Was the "pre" OHE score from participant recall and were items like "confidence" scored on a Likert-style scale? From a qualitative look at the data, it appears that dental professionals who were participating because of inexperience working with very young children benefitted from the program. A chi-square to compare the dental providers change in scores from baseline might add meaningful data as states consider whether to include dentists or only medical professionals in OHE training.

The second point of clarification is related to "implementation" as reported in Table 2. If I understand correctly, providers who performed each care item at a rate greater than $50 \%$ with eligible children were considered to have "adopted" the lessons from the OHE program. I think the assessment item for "implementation" is designed to capture repeated care of those same eligible children 12 months later (maintenance). Is it correct to read the 12-month column in Table 2 as the "adoption" data and the 24-month column as the "implementation/maintenance" data? It was noteworthy that after 24 months, the 2009 cohort had continued to increase the provision of every care item.

The third question for the research team is regarding the distinction between medical professionals and non-dental professionals from a professional scope-of-practice perspective. My assumption is that the providers of patient care whose responses are 
reflected in Table 2 included participants from the medical, dental, and nursing professions $(\mathrm{n}=71)$. The authors reported in their discussion that the barrier related to "lack of adequate reimbursement" may have been a result of public health professionals not being eligible for reimbursement. My question is if billing code D1206 can be delegated. When a non-dental professional eligible for reimbursement performs the care then the V20.2 code could be used. In cases where the individual is not reimbursable, are there opportunities for the task to be delegated to them by the supervising prescriber and billed simply as D1206? I also wondered about the role of nurse practitioners and physician assistants in the expansion of oral health care into well-child visits. More than 700 participants in the OHE were surveyed. Were any of them mid-level providers?
I would like to restate my appreciation of this work documenting the positive impact of the Colorado OHE program for increasing oral health care delivery in the non-dental setting. I thank the authors in advance for considering my questions.

\section{Disclosure}

The author reports no conflicts of interest in this communication.

\section{Reference}

1. Braun PA, Racich KW, Ling SB, et al. Impact of an interprofessional oral health education program on health care professional and practice behaviors: a RE-AIM analysis. Pediatric Health Med Ther. 2015;2015(6):101-109. 


\section{Author's response}

\section{Patricia A Braun \\ University of Colorado Anschutz School of Medicine, Aurora, CO, USA}

Correspondence: Patricia A Braun

Children's Outcomes Research Program, University of Colorado Denver I 3 I 99 E Montview Blvd, Suite 300 F443, Aurora, CO 80045, USA

Email patricia.braun@ucdenver.edu

We appreciate Dr Larsson's detailed reading and enthusiasm of our work. We would like to address all three of her points/ questions. First, Dr Larsson asked a variety of questions related to how we measured the effectiveness of the oral health education (OHE). To better understand our responses, we would like to review that the 2009 participants were surveyed 12 and 24 months after receipt of the OHE, and the 2011 participants were surveyed 12 months after OHE receipt. Participants who completed each survey did so anonymously; therefore, comparisons between responses across survey years and across 2009 and 2011 cohorts were across groups and not across individuals. This was mentioned as a limitation in our discussion. Because the participants' responses were anonymous, we were unable to know if the same 2009 participant answered both the 12- and 24-month surveys and therefore chose to compare their responses with both one- and two-sample chi-squared tests. We used two-sample chi-square tests to compare responses between the 2009 and 2010 cohorts and between the medical and dental providers (given that each of these aforementioned groups was unique).

We measured the effectiveness of the Cavity Free at Three OHE by measuring the participants' confidence in providing preventive dental services after OHE receipt. Recognizing that some participants may have been confident in care delivery prior to OHE receipt, we asked participants, "BEFORE the Cavity Free at Three Oral Health training, how confident were you in providing < care component $>$ ?" A separate question was asked for each of the following care components: assessing risk for childhood caries, examination of the teeth, applying fluoride varnish, demonstrating the brushing of a child's teeth, providing anticipatory guidance on the prevention of cavities, and using caregiver goal setting to change parent/caregiver oral health behaviors. We then asked participants, "AFTER the Cavity Free at Three Oral Health training, how confident were you in providing $<$ care component $>$ ?" Answers to all of these questions were on a four-point Likert scale (very confident, somewhat confident, not very confident, and not at all confident).
For clarification of Dr Larsson's comments, we did not state that we compared pre-/post-training scores on key variables as suggested in the letter to the editor, however, we did state, "We measured the effectiveness of the OHE by assessing the participants' pre-/post-training confidence and knowledge, attitudes, and beliefs regarding their provision of oral health preventive services (OHPS)." In our results, we report the pre- and post-training confidence levels but did not report comparisons between pre-/post-training scores. We were reluctant to make these comparisons given that the responses to each of the surveys may have been from different individuals as mentioned above. This is a limitation to our findings as we have stated. The proportion of medical and dental providers who reported they were confident (very/ somewhat) prior to OHE training were reported in the first paragraph of the effectiveness section of the results; their post-training confidence levels were reported in the second paragraph. To describe the results in a slightly different manner as suggested by Dr Larsson: medical professional reported pre-/post- training confidence in examination of the teeth (14\%/88\%); caries risk assessment (14\%/86\%), fluoride varnish application $(5 \% / 81 \%)$, oral health instruction $(27 \% / 93 \%)$, and caregiver goal setting (13\%/83\%). Dental professionals reported pre-/post-training confidence in examination of the teeth $(67 \% / 97 \%)$; caries risk assessment (54\%/96\%), fluoride varnish application (67\%/100\%), oral health instruction $(99 \% / 100 \%)$, and caregiver goal setting (48\%/96\%). The confidence of both medical and dental professionals in delivery of all care components substantially increased after receiving OHE and this suggests that both groups benefitted from the OHE. As suggested in Dr Larsson's letter to the editor, other states should consider providing training to dental professionals as well as medical.

We respond to Dr Larsson's second point. In Table 2, we described 12- and 24-month findings as program "implementation," but as Dr Larsson suggested, the 12-month findings could also be interpreted as program "adoption" and the 24-month findings as "implementation/maintenance." As seen in Table 2, the proportion of health care professionals who reported they provided the various care components to $>50 \%$ of the eligible patients seen in the past 2 weeks was higher on the 24-month survey than the 12-month survey. While this does suggest program maintenance, we recommend using caution in interpreting these findings as the 24-month survey response rate was lower than the 12-month response rate and the 24-month respondents may have been more likely to have been providing the care than nonrespondents. Nevertheless, these findings are encouraging. 
The following comments are in response to Dr Larsson's third question. In Colorado, the application of FV (D1206) can be delegated; however, it needs to be provided in conjunction with a V20.2 well-child care visit for children up to age 5. We would like to point out that Colorado's 2009 Medicaid D1206 policy allows for reimbursement to both physicians and allied health professionals (mid-levels); all can receive reimbursement for D1206 if they are licensed in Colorado, have received the OHE, and the D1206 procedure was provided at a V20.2 well-child care visit. Both physician's assistants and nurse practitioners received the OHE and their responses were included in our results. However, public health nurses (not nurse practitioners) also received the OHE but cannot receive reimbursement for the D1206 service.

We thank Dr Larsson for her interest in our work.

\section{Disclosure}

The author reports no conflicts of interest in this communication.

Dove Medical Press encourages responsible, free and frank academic debate. The content of the Pediatric Health, Medicine and Therapeutics 'letters to the editor' section does not necessarily represent the views of Dove Medical Press, its officers, agents, employees, related entities or the Pediatric Health, Medicine and Therapeutics editors. While all reasonable steps have been taken to confirm the content of each letter, Dove Medical Press accepts no liability in respect of the content of any letter, nor is it responsible for the content and accuracy of any letter to the editor.

\section{Publish your work in this journal}

Pediatric Health, Medicine and Therapeutics is an international, peerreviewed, open access journal publishing original research, reports, editorials, reviews and commentaries. All aspects of health maintenance, preventative measures and disease treatment interventions are addressed within the journal. Practitioners from all disciplines are invited to submit their work as well as healthcare researchers and patient support groups. The manuscript management system is completely online and includes a very quick and fair peer-review system. Visit http://www.dovepress.com/ testimonials.php to read real quotes from published authors.

Submit your manuscript here: http://www.dovepress.com/pediatric-health-medicine-and-therapeutics-journal 